\title{
KNOWLEDGE MANAGEMENT AND ITS IMPORTANCE IN MODERN ORGANIZATIONS
} https://doi.org/10.47743/jopafl-2021-20-19

\author{
Gbosien Chris SOKOH \\ Department of Political Science, Delta State University Abraka \\ Delta State, Nigeria \\ sokohgc@gmail.com \\ Ugo Chuks OKOLIE \\ Department of Political Science, Faculty of the Social Sciences, Delta State University, \\ Abraka, Nigeria \\ ugookolie3@gmail.com
}

\begin{abstract}
With the current economic trend, every organization want to successfully implement business strategies, achieve their business objectives, optimize the use of human resources and gain competitive advantage. Knowledge management is critical for an organization to properly utilize it resources and create a sustainable competitive edge. It is against this backdrop that this paper examined the importance of Knowledge management in modern organizations. This paper relies on secondary data and utilizes the content analysis for interpretation of collected data. This paper concludes that quality efficiency and effectiveness in performance cannot happen if employees are not developed. Today organizations compete on the basis of knowledge since products and services are increasingly complex. This is why the requirement for a life-long learning has become an unavoidable reality.
\end{abstract}

Keywords: Knowledge management, competitive advantage, Success factors, performance

\section{Introduction}

Knowledge management is concerned with the entire process of discovering and the creation of knowledge, dissemination of knowledge and the utilization of knowledge. Knowledge management principles recognize that it is important for organizations "to know what they know”. All businesses inherently store, access and deliver knowledge in some specific manners. Knowledge is required in other to enjoy an outstanding competitive advantage. Awan and Jabbar (2015), Ahmed and Mohamed (2017) stated that proper knowledge management improves the performance of organizations whether it is public or private. They also emphasized that the retention and proper training of employees not only improve their skills but also build up confidence in them. The creation of knowledge is essential for the survival of any organization. Knowledge is an activity that happens throughout daily work activities and this is required for their survival in a competitive market. These could be by formal training or talking with those who share similar interests or by technical mechanism such as data mining activities. Knowledge creation is primarily a human process where technology can facilitate knowledge creation but cannot replace people and hence their continuous development and improvement. Therefore, it is logical to conclude that the ability to create knowledge and generate a competitive advantage is essential for any organization that wishes to remain relevant and be able to achieve wider 
market share that is sustainable as this will in turn produce excellent performance. Performance involves a complex series of actions that integrate skills and Ahmad knowledge to produce valuable results. Examples include designing, selling, production, playing a sport and other activities involved in solving a problem. In some instances, the performer could be an individual, a collection of people who are collaborating such as an academic department, research team and student's team. Performance is a journey and not a destination. Different locations in the journey provides for different levels of performance. Each level defines the efficiency, quality and effectiveness of performance (Akram \& Hilman, 2018; Onyango, 2018). This paper therefore examined the importance of Knowledge management in modern organizations.

\section{The concept of knowledge}

Knowledge is the insight, understanding and practical know-how that we all possess. It is the fundamental resource that allows us to function intelligently (Odiri, 2014). From the above definitions, it is clear that knowledge is an invisible or intangible asset. Its acquisition involves complex cognitive processes of perception, learning, communication, association and reasoning (Akinyemi, 2007). Davenport and Prusak (2005) affirmed that knowledge is derived from information and information is obtained from data. They posited that information is changed into knowledge by a process of comparison, connections (by understanding relations), and conversation (to uncover what others think about the same information) and results (how information affects decisions). This is stored in the form of organizational processes, know-how, policy manuals, customer, best practices, management information system (MIS), culture and norms. Therefore, knowledge is the whole body of cognition and skill which individuals use to solve problems. It includes theories, practices, everyday rules and instructions for action. Knowledge is based on data and information and always bound to persons. It is constructed by individuals and represents their beliefs about causal relationship (Aygul \& Bahtisen, 2017).

This definition agrees with the opinion of other writers such as Nonaka and Takeuchi (1995) and ou-yang (2014:6) who saw "knowledge as a process that involves human action, noting that knowledge is both complex and multifaceted”. Bladder (1995) as cited in Armstrong (2006:16) viewed it as being "situated and abstract, implicit and explicit, distributed and individual, physical and mental, developing and static, verbal and encoded". He therefore categorized forms of knowledge as embedded in technologies, rules and organizational procedures, uncultured as collective understanding. Others include values and beliefs, embodied into practical activity-based competencies and skills of key members of the organization (i.e. practical knowledge or know-how) embraced as the conceptual understanding and cognitive skills of key members (conceptual know-how or knowledge). Following Nonaka's (1991) view that knowledge is held either by individuals or on a collective basis, Bladder also added that embodied or embraced knowledge is individual while embedded and cultural knowledge is collective (Akinyemi, 2007). According to Drucker (1989), knowledge is information that changes something or somebody either by becoming grounds for actions or by making an individual (or an institution) capable of performing different or more effective action. Considering the definitions so far, a cursory look at the concept of knowledge shows that it is reflected in 
the form of ideas, judgments, talents, root causes, relationships perspective and concepts. It is stored in the individual brain or encoded in organizational processes, documents, products, services, facilities and systems (Grey, 2002).

\section{Current Approaches to the Study of Knowledge Management}

There are of course many ways to slice-up the multi-faceted world of knowledge management. The approaches vary by author and school. Despite this difference, knowledge management can be viewed from each of the following perspectives:

- Techno-Centric- A focus on technology, ideally those that enhance knowledge sharing/growth.

- Organizational - This has to do with "how does the organization need to be designed in order to facilitate knowledge processes which organizations work best with what processes."

- Ecological - Seeing the interaction of people, identity, knowledge and environmental factors as a complex adaptive system.

However, Popov and Vlasov (2014: 813) “identified two broad tracks of knowledge management and these include management of information and management of people. Management of information to researchers regard knowledge as being equal to objects that can be identified and handled in information systems while management of people as seen by researchers and practitioners in the field consist of processes, a complex set of dynamic skills, know-how, that is constantly changing. A critical look at this categorization tends to suggest that its characterization is tilted more on target and did not capture the full flavor of the important distinction in approaches to organizational knowledge management”. This led to a three-part categorization of "Knowledge Praxis" as follows:

- Mechanistic approach to knowledge management;

- Cultural/behaviorists approach to knowledge management; and

- $\quad$ The Systematic approach to knowledge management.

\section{Mechanistic Approach to Knowledge Management}

"Mechanistic approaches to knowledge management are characterized by the application of technology and resources to do more of the same job in a better way. The main assumptions of this approach include:

- Better accessibility to information is a key for enhanced methods of access and reuse of documents (hypertext linking, database, full-text search, etc).

- Networking, technology in general (especially intranets), and groupware in particular, will be key solutions.

In general, technology and share volume of information will make it work” (sayed, 2015: 167).

\section{Cultural/Behaviorist Approach to Knowledge Management}

The cultural/behaviorist approach with substantial roots in process re-engineering and change management tend to view knowledge problem as a management issue. "This approach tends to focus more on innovation and creativity (the learning organization) than 
on leveraging existing explicit resources or making working knowledge explicit. The basic assumptions of this approach are:

- Organizational behaviour and cultures need to be changed dramatically. In an information intensive environment, organizations become dysfunctional relative to business objectives.

- Organizational behaviours and culture can be changed but traditional technology and methods of attempting to solve the knowledge problem have reached their limits of effectiveness. A hostile view is therefore required. In this case, theories of behavior of large-scale systems are often invoked.

- It is the processes that matter not the technology.

- Nothing happens or changes unless a manager makes it to happen” (Wang, Noe \& Wang, 2016: 978).

\section{Systematic Approach to Knowledge Management}

The systematic approach to knowledge management retains the traditional faith in rational analysis of the knowledge problem. It presupposes that the problem can be solved, but new thinking of many kinds is required (Davenport \& Klahr, 1999). Its basic assumptions include the following:

- It is the sustainable results that matter and not the processes or technology or even the definitions of the term knowledge.

- A resource cannot be managed unless it is modeled and many aspects of the organization knowledge can be modeled as an explicit resource.

- Solutions can be found in a variety of disciplines and technologies and traditional methods of analysis can be used to re-examine the nature of knowledge work and to solve the knowledge problems.

- Cultural issues are important but they too must be evaluated systematically. Employees may or may not have to be 'changed but policies and work practices must certainly be changed and technology can be applied successfully to business knowledge problems themselves (Daft, 2012).

- Knowledge management has an important component, but it is not an activity or discipline that belongs exclusively to managers (Bergeron, 2003).

A critical look at these three approaches identified above reveals the following:

The Mechanistic approach to knowledge management appears relatively easy to implement for corporate political reasons because the technologies and techniques (although sometimes advanced in particular areas) are familiar and easily understood. It makes some good sense, because it enhances access to corporate intellectual assets. But this approach is simply not clear about whether access itself will have a substantial impact on business performance especially as mountains of new information are placed on line, Unless the knowledge management approach incorporates methods of leveraging cumulative experience, the net result may not be positive and the impact of implementation may not be measurable than traditional models (Gao, Li \& Nakamori, 2008). Regarding the cultural/behaviourist approach to knowledge management, the cultural factors that may affect organizational change have almost certainly be undervalued and cultural/behaviourist implementations have shown some traits of benefits. But the causeeffect relationship between cultural strategy and business benefits is not clear because the 
"Hawthorne Effect" may come into play and because we still cannot make dependable predictions about a system as complex as knowledge, positive results achieved by cultural/behaviorist strategies may not be sustainable, measurable, cumulative or replicable.

Finally, an assessment of the systematic approach to knowledge management reveals that unrepentant rationalists in the business world are taking a systematic approach to solving the knowledge problem. A closer look will also reveal evidence of such approaches as well as less formal use of the term 'systematic knowledge management'. Systematic approach is the most promising for positive cumulative impact, measurability and sustainability (Holsapple \& $\mathrm{Wu}, 2011$ : 274). Considering the various approaches to the study of knowledge management, it is evident that the discipline is growing. There is an increasing presence of academic debates within epistemology, emerging in both theory and practice. United Kingdom and Australian Standard Bodies have both produced documents that attempt to bind and scope the field but these have all received limited acceptance or awareness (Lekhanath \& Santosh, 2017: 87). Knowledge management has always existed in one form or another. Examples include on-the-job peer discussions, formal apprenticeship, discussion forums, corporate libraries, professional training and mentoring programmes. However, with computers becoming more widespread from the second half of the 20th Century, specific adaptations of technology such as knowledge base, expert systems, and knowledge repositories have been introduced to further enhance the process.

\section{The Importance of Knowledge Management (KM)}

Ibrahim and Reig (2009) postulated that knowledge management is critical for an organization to create a sustainable competitive advantage. They added that knowledge management initiatives help to improve business processes. Organizations can reduce business processing time simply because they can also provide best practices. Business processes can also be improved upon through conversations and discussions. These can generate valuable knowledge forecast saving and cost reduction. In their views they concluded that "knowledge management activities can improve organization's operational activities. This could happen in a variety of ways such as reducing the design cycle time, lead time and cost reduction time. Others include product to market and product quality improvement. If information is the currency of knowledge economy, human enterprise therefore is the bank where it is kept, invested and exchanged to create the right value for the economy. Factors that drive the need for knowledge management include organizational survival, competitive differentiation, globalization effects and aging work force. Considering the management dynamics today, the core of managing knowledge requiring utmost focus for work activities is information best” (Roy \& Sivakumar, 2011: 6 ). The need for knowledge management is the realization that an organization must manage its knowledge. The business survives on this in today's dynamic and competitive market place. Survival concerns are not limited to profit firms as nonprofit public agencies have all realized the value of knowledge. Desouza (2011) pointed out that without adequate care in how knowledge is managed, organizations will not be operating optimally. This will result in the ineffective and inefficient creation and delivery of products and services. This can lead to dissatisfaction among customers which may influence the demise of the 
organization. Conducting knowledge management helps in competitive differentiation. This is because all organizations, whether for profit or non-profit compete within a sector of the economy.

Knowledge management is a critical driver of competitive advantage because it enhances the capacity of organizations to innovate, thereby differentiating itself from its competitors. Organizations that are unable to innovate to a sustainable level will lack the ability continuously to attract new customers. In turn, this will lead to their demise. On the other hand, organizations that are able to innovate will be able to secure and even retain their competitive positions in the market place (Desouza, 2011). Globalization today has also provided the need for knowledge management, as organizations search to find effective tools and methods for acquiring and sharing knowledge over many structural and cultural barriers. This position has created an urgent need for organizations to be able to manage knowledge across countries and continents. The aging workforce brings to light how knowledge will leave the organization. This requires that the intellectual capital (HRM) be captured. This is to ensure that the work environment is not under threat by reinventing knowledge. Epetimehin and Ekundayo (2011: 11) revealed that "knowledge management efforts help organizations to share valuable organizational insights. This is necessary to reduce redundant work to avoid reinventing the wheel, to training time for employees”. This will lead to the adaptation to changing environment and markets.

\section{Steps in Creating Knowledge Management Strategy for an Organization}

With the need for proper knowledge management in an organization, the desire to create a knowledge management strategy cannot be ignored. In the process of trying to create a knowledge management strategy for an organization, five major steps are clearly itemized and explained below:

Identification of the knowledge to be systematically managed by the organization

This is the first step in creating knowledge management strategy by the organization. The most important aspect of this knowledge is that it is of high value, that is, the knowledge that is expensive to create. Considering this aspect, it is not surprising that the national laboratories of the United States Department of Energy (DOE) would be one of the first places where comprehensive management efforts was initiated (Salisbury \& Plass, 2001). In addition, this high value knowledge unit should also be the same knowledge that makes up the "core competency" of the organization. For example, the knowledge identified for management by the DOE laboratories by Salisbury and Plass (2001) makes up their core processes. Any knowledge that is not directly related to the core competency of the organization can be outsourced. That is, it can be purchased from an outside supplier. All other knowledge that makes up the core competency of the organization should be explicitly managed by the organization. To develop a strategy to manage this knowledge, we revisit the business strategy for the organization, identify the performance gap between the current workflow and the work flow required to achieve the business strategy for the organization, modify the current workflow to achieve the business strategy, and determine the knowledge transfer needs of the organization to accomplish the work in the modified workflow (Karuoya \& Thomas, 2017). 
Re-visiting the Vision, Values and Business Strategies of the Organization

Identifying the core competence knowledge of an organization begins by re-visiting the vision, values and business strategies of the organization. If these are not clearly understood, there is urgent need for them to be clarified through some sort of organizational development intervention. The vision and values of the organization drives the business strategy of such business unit. This business strategy automatically becomes the "roadmap" for the resulting knowledge management system since it describes what the organization plans to do and not what it is doing at the moment (Odiri, 2006). This means that a systematic knowledge management solution is not instituted to support work in the organization as it is seen today but to support the organization in achieving its business strategy.

\section{Identifying the Current Workflow process of the Organization}

This is considered a very difficult task in the steps involved in creating a knowledge management strategy. To accomplish this difficult task, it is necessary to apply those techniques taken from the area of contextual inquiry, a means to gather computer system requirements by using anthropological field techniques on potential end-users of the system, according to (Beyer \& Holtzblatt, 1997). One major fact identified is that work has become so habitual for the people who do it that they often have difficulty articulating exactly what they do and why they do it. To address this issue, Beyer and Holtzblatt employed one-on-one field interviews with end-users in their workplaces to discover what tasks are to be accomplished in their work. As a result of this process the interviewer and the end-users need to create a shared interpretation of that work and how it will be done on an ongoing basis. In addition they used this shared interpretation to create the major processes of a workflow model for the end-users of the system (Odiri, 2014). This model as depicted hereunder shows the major processes of an example of a workflow for an organization.

\section{Workflow Model}

Source: Odiri (2014).

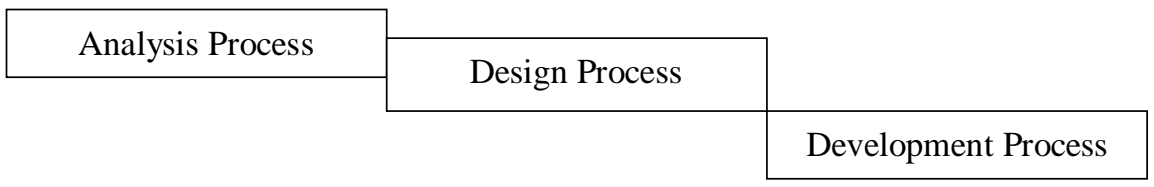

Comparing with the Business Strategy of the Organization

After the current workflow of an organization has been created, the next stage is to compare it with the business strategy of the organization. What is done here is to identify the performance and learning gap that may exist between what the organizations is doing and what it plans to do. To close this gap a major re-examination of the current workflow for the organization is carried out thereby creating room for changes to the workflow (Odiri, 2014). Old processes may need to be removed or new ones added to modify the workflow so that the planned business strategy can be fully achieved. 
Determining the Knowledge Transfer Needs through the development of a Knowledge Management Strategy

The next and final step in creating knowledge management strategy for an organization is the determination of the knowledge transfer needs through the development of a knowledge management strategy. This means determining the knowledge transfer needs for the organizations that are required to achieve the business strategy. This, in simple language refers to the percentage of practitioners and experts that will use the system in future (Odiri, 2014). For example, if traditionally, there is a high level of turnover in the organization, and then there will be need to support the novices. Also, if the organization has as part of its business strategy to retain and support the skill development of its more experienced members (Practitioners), then the resulting system should provide access to more procedural knowledge through example procedures. In a similar vein, if the organization's business strategy includes leveraging the expertise of its longtime members (experts) then the resulting system should provide these members with opportunities to share their meta cognitive knowledge through adding expertise to the decision support resources (Seyed, 2017).

\section{Success Factors Supporting Knowledge Managements}

Okunoye (2002: 20) has provided "knowledge management enablers (or inflowing factors) as organizational mechanisms for intentionally and consistently fostering knowledge. These enablers are management leadership and support, information technology, strategy and purpose measurement, organizational infrastructure processes activities, motivational aids, training and education human resources management. Management leadership and support is vital to the success of knowledge management. They are important in acting as models to exemplify the desired behaviour for knowledge management. To do this requires a willingness to share and offer their knowledge freely within others in the organization". In addition, there has to be a continuous learning and to search for new knowledge and ideas, they are to model their behaviours and actions. The supporting factors include:

\section{Organizational Culture}

Salman and Sumaiya (2017: 38) defines culture as "the core benefits; values, normal, and social customs that govern the way individuals act and behave in an organization. Culture is supportive of knowledge management because it is one that highly values knowledge and encourages its creation, sharing and application. Knowledge sharing and transfer requires individuals to come together to interact, exchange ideas and share knowledge with one another". Beyond that there is also the need for innovative culture in which individuals are constantly encouraged to generate new ideas, knowledge and solution and openness should be demonstrated by the leadership to ensure trust.

\section{Information Technology (I.T)}

IT pushes towards rapid research, access and retrieval of information and can support the collaborative and communication between organizational members. It should be noted that knowledge - based collaboration, content and document management portals customer relationship management, data mining, workflow search and e-learning are 
important factors that need to be considered in the development of a knowledge management system to include its simplicity of technology care of content and standardization of knowledge structure and ontology (Wong, 2005 cited in Salman and sumaiya, 2017: 40).

\section{Organizational Infrastructure}

To develop an appropriate organizational structure requires the establishment of roles and teams to perform knowledge related task. Among these roles is one of the chief knowledge officers (CKO) (Valmohammadi \& Ahmadi, 2015: 135). He or she is to coordinate, manage and set the cause for knowledge management.

\section{Processes and Activities}

This refers to something that can be done with knowledge in the organization. To this end, Valmohammadi \& Ahmadi, (2015:137) identified four main processes as creation, storage/retrieval, transfer and application. The survival of these components would depend largely on appropriate intervention and mechanisms to be put in place to address them. By incorporating employees into the process, knowledge sharing, technological networking tools could be supplemented with face to face discussion as this can provide a richer medium for transferring knowledge.

\section{Measurement}

Measurement acts as a data collection system that gives useful information about a particular situation or activity. Measurement is needed to demonstrate the value and worth of a knowledge management initiative to management and stakeholders. This is because without such evidence and confidence from top management to sustain it, it will diminish (Wong, 2005 cited in Salman and sumaiya, 2017: 40).

\section{Motivation Aids}

This has to do with the development of a grassroots desire amongst employees to tap into their company's intellectual resources. If individuals are not motivated to practice knowledge management, no amount of investment, infrastructure and technological intervention will make it effective. Therefore the right incentive, rewards or motivational aids are required to encourage people to share and apply knowledge. This will help to stimulate and reinforce the positive behaviours and culture needed for effective knowledge management. Linking rewards solely to individual performance on outcomes which can result in competition will certainly be detrimental to knowledge sharing culture (Hayat \& Riat, 2011: 473).

\section{Strategy and Purpose}

Strategy and purpose provides the foundation for an organization to deploy its capabilities and resources to achieve its knowledge management goals. This can only happen only if management is to support an imperative business issue of the organization. This perspective seems to be in agreement within the literature that it has to be linked or integrated with the enterprise business strategy (Valmohammadi \& Ahmadi, 2015: 135). It is also essential that employees support this vision and believe that it will work alongside 
clear objectives, purposes and goals properly put in place, towards a knowledge management effort.

\section{Training and Education}

Training and education is required for employees to make them have a better understanding of the concept of knowledge management. Employees could be trained and educated in using the knowledge management system and other technological tools for managing knowledge. To this end, there will be the full utilization of the potential and capabilities offered by these tools. From training, individuals are able to understand their new roles for performing knowledge related tasks. Equally important, is to equip them with the skills to foster creativity innovation and knowledge sharing. Horat cited in Hayat \& Riat (2011: 473) suggests that for effective knowledge management, skills development should occur in the following areas; communication, soft networking, peer learning team building, collaboration, and creative thinking.

\section{Resources}

The proper implementation of knowledge management requires resources. This is because financial support is inevitably needed if an investment in a technological system is to be made, for example human resources are needed to co-ordinate and manage the implementation processes as well as to take up knowledge - related roles. Time is needed by organizations for their employees to perform knowledge management activities such as knowledge sharing (Hayat \& Riat, 2011: 475).

\section{Areas of Application of Knowledge Management in Organizations}

Some basic questions as to which area of an organization can knowledge management is applied tend to agitate the minds of many top managers of businesses. From researches carried out, it has been discovered that applications of knowledge management in organizations typically fall into the following broad categories.

Knowledge database and repositories (explicit knowledge) - storing information and documents that can be shared and re-used e.g. client presentations, competitors intelligence, customers data, marketing materials, minutes of meetings, policy document, price lists, product specifications, project proposals, research reports, training packs (Thomas \& Bizer, 2013).

Knowledge route maps and directories (tacit and explicit knowledge) - pointing to people, document, collections and datasets that can be consulted e.g. yellow pages, export locators containing curriculum vitae, competency profiles and research interests.

Knowledge networks and discussions (Tacit knowledge) - providing opportunities for faceto-face contacts and electronic interaction, e.g. establishing chat facilities/talk rooms, fostering learning, group and holding "best practice" sessions. These above mentioned can be easily found in all sectors of business and industry especially among processional service organizations and manufacturing concerns inclusive (Shih, Chang \& Lin, 2010: 76).

\section{Objectives and Successes of Knowledge Management}


Being a fairly new research area, opinions about the paths, method and even the objective of knowledge management vary. Many theorists such as Sanchez (1997), Grant (2006) and Cohen (2008) in their studies agree, however, that knowledge management has two main objectives. These are Efficiency and Innovation. Efficiency means using knowledge to improve productivity by increasing speed or reducing cost. Example of this could be when management consultants to a firm spread its employees' knowledge to others for use in order to save time and come up with better solution for its clients. Innovation on the other hand is concerned with using it to generate new products and services, new businesses and new business processes. Example of this could be when technological firms want to collect and stimulate the knowledge of its employees in order to create new products. Using knowledge for efficiency means deepen the knowledge of the organization to leverage the existing knowledge. While using knowledge for innovation means widen the knowledge of the organization thereby creating new knowledge. To obtain a true learning organization, an organization has to use knowledge for both efficiency and innovation. Knowledge management theorists have however stated that a company has to focus its knowledge management efforts on either enhancing innovation (knowledge for innovation) or on increasing efficiency (knowledge for efficiency) (Hankanson, 2010).

Various researches have shown that companies usually adopt two broad thrusts in applying knowledge management in organizations. These are through the sharing of existing knowledge better (making implicit knowledge more explicit and putting in place to move it more rapidly to where such knowledge is needed) and innovation (making the transition from ideas to commercialization more effective) (Bosua \& Venkitachalam, 2013). Hence, knowledge management programmes are seen as having typically one or more of the following activities identified below:

- Appointment of a knowledge leader to promote the agenda and develop framework.

- Creation of knowledge team by bringing people from various disciplines to develop the methods and skills.

- Development of knowledge bases through best practices, expertise directories, market intelligence

- Enterprise intranet portal - a one-stop-shop that gives access to explicit knowledge as well as connections to experts.

- Knowledge centre as focal points for knowledge skills and facilitating knowledge flow.

- Knowledge sharing mechanisms such as facilitated events that encourage greater sharing of knowledge than would normally take place and

- Intellectual asset management which includes methods of identifying and accounting for intellectual capital.

The proper application of those above mentioned knowledge management activities in various organizations have helped such organizations to achieve significant benefits (Seyed, 2015). Some of these organizations that have achieved significant success through knowledge management are as follows:

- Hoffman La Roche - through its Right First Time Programme had reduced the cost and time to achieve regulatory approvals for new drugs,

- Dow Chemical - By focusing on the active management of its patent portfolio have generated over 125 million dollars in revenue from licensing and other ways of exploiting their intangible assets. 
- British Petroleum (BP) -By introducing virtual team working using video conferencing have speeded up the solution of critical operations problems.

- Texas Instruments - By sharing best practice between its semiconductor fabrication plants saved the equivalent of investing in a new plant.

- Sandia Assurance - By developing new measures of intellectual capital and goaling their managers on increasing its value have grown revenues much faster than their industry average.

- Hewlett Packard (HP) - By sharing expertise already in the company, but not known to their development teams now bring new products to market much faster than before.

These successes so far recorded are however hinged on the following guidelines according to research. These are what Skyrme (2003) classified as "guidelines for success" and they are as follow:

- There is need to have a knowledge leader or champion. This should be someone who can actually and actively drive the knowledge agenda forward, create enthusiasm and commitment.

- $\quad$ There is need to have "Top Management Support" (Cohen, 2013). This means that there is need to have a Chief Executive Officer (CEO) who recognizes the value of knowledge and who actively supports the knowledge team in its workplace.

- There should be a clear value proposition. This means identification of the link between knowledge and the bottom line business benefits, a new measure of performance and appropriate rewards to delight the organization and customers.

- There should be a compelling vision and architecture which will act as a framework that drives the agenda forward.

- There should be the creation of a culture that supports innovation, learning and knowledge sharing with a reward structure (Cohen, 2013). This is usually supported by appropriate reward mechanisms.

- There should be a technical infrastructure that supports knowledge work. This should span from simple knowledge support tools to intranets, and ultimately to move sophisticated groupware and decision support. Simulation, data mining and good document management also have a role to play here.

- The presence of systematic knowledge processes supported by specialists in information management (librarians) with close partnership between users and providers of information is equally very essential. The biggest and major challenge to successful knowledge management practice in organization has been that of changing the culture from "knowledge is power" to "knowledge sharing is power" Thomas \& Bizer (2013).

Other common obstacles identified are:

Finding time - with so many initiatives demanding for attention, it is easy to sideline more challenging issues like knowledge management. However, those organizations that have committed resources and have knowledge champions have achieved outcome that far surpass their level of inputs

Introversion - people are afraid to learn from outsiders or even expose internal operations to customers.

To be focused on detailed process rather than the big picture and the more chaotic process of knowledge creation. 
Treating it as one-off project or quick-win. Knowledge management should be viewed as a commitment to the long-term organization's future prosperity.

Seeing knowledge management as individual discipline and 'turf wars'. Knowledge management actually goes beyond the limit of any single function or discipline. Therefore all functions must collaborate with each other.

Finally, it has been observed that organizational recognition and reward systems usually do not sufficiently recognize knowledge contributions. They are linked to traditional financial measures (Skyrme, 2003; Shih, Chang \& Lin, 2010).

All these identified challenges are, however, not overcoming. Implementing successful knowledge management requires a systematic change and project management approach. However, it is more than just a project. Over time, knowledge management changes the way that people work so that their individual knowledge is more effectively harnessed for the benefit of all.

\section{Identifiable Strategies that could be employed by Organizations to Manage Knowledge}

This has to do with organizations in their day-to-day operational attempting to identify, capture, and then leverage knowledge. Knowledge that is being employed within an organization may not be easily leveraged especially the tacit knowledge. Explicit knowledge by its nature appears easier to leverage than the tacit one. Organizations look onto other organizations to obtain the critical information necessary to remain competitive. Since the basis for the competition in the 1990s and beyond has shifted towards how well knowledge and other intellectual assets are focused on reducing cost, increase speed and meeting customers' needs, it has become quite evident that the mere possession of knowledge is not enough. Concerted effort must be made to identify, tap and use the knowledge that exists within an organization (Skyrme, 2003). According to Toffer, 1990 cited in Cohen (2013: 76), knowledge is considered to be "the source of power and no longer just an adjunct of money and muscle but instead the key element of power". This was again complemented by Ibrahim and Reig (2009: 107) when they said that the economic power of a modern corporation lies in its intellectual and service capability instead of its hard assets. they pointed out that the value of most products and services now depend on "knowledge-based intangibles" such as technical know-how, product design, marketing presentation, understanding customer's personal creativity and innovation (Shih, Chang \& Lin, 2010).

As a result of the growing interest in the area of knowledge management as it affects organizations, the American Productivity and Quality Center in a research carried out between 1992 and 1995 came out with six primary strategies which organizations can adopt in the process of addressing their knowledge management needs. They are:

The pursuit of knowledge management as a business strategy: This considers the proper management of knowledge as central to the growth and survival of all organizations. It therefore becomes a matter of necessity that organizations at all times should strive to pursue this strategy. The key issue here is for organizations to identify, tap and use the knowledge that exists both within the organization (employees and all other stakeholders) and outside the organization (Shih, Chang \& Lin, 2010). 
Transfer of Knowledge and Best practice: This strategy focuses on "the systematic approaches to knowledge re-use and transfer of best practices and knowledge to where organizations can use them to improve on their operation or include them in their product and services. The design is comprised of systems and priorities to obtain, organize, repackage and distribute knowledge within the organization. In this strategy, knowledge sharing and transfer of best practice is seen to have great impact on performance hence the need to make knowledge available at points of action in order to realize its value. Also, this strategy emphasizes the importance of team relationship and networks as a basis for effective transfer of knowledge. Since mere documentation of a practice do not itself guarantee knowledge transfer, this strategy emphasized the need for the sharing of knowledge among people informally without capturing it in some-form of "corporate memory" but through structured mechanisms and team approaches. Informal sharing of knowledge can be deep, creative and unexpected while establishing long lasting effective networking” (Shih, Chang \& Lin, 2010: 77). Organized knowledge sharing can reach much broader populations with greater value to the organization but may stifle some of the spontaneous and creative aspects of the informal sharing modes. The main approaches of this strategy comprises of:

The Learning Organization Approach: In this approach, the organization learning cycle encompasses data, information, knowledge intelligence, strategy plans, actions and assessments. Here, the organization would use all information to assess gaps, feed data and then make adjustments for the next cycle. It involves transferring the benefits generated by this process from one part of the organization to other parts of the organization (Cohen, 2013).

Networking Approach: This approach also, enables organizations achieve success with the help of intellectual assets team. The team comprised of people from various business units who provide a network for spreading best practices within the organization. This team could comprise the organization's marketing managers, research managers, and others who meet regularly to put together an Intellectual Asset Management portfolio with its analysis. The proper functioning of this team will add credibility to the Intellectual Asset Management function and this represents a powerful means of getting business management to accept ideas (Seyed, 2017).

Practice Centers and Communities of Practice Approach: This involves marketing successful endeavors and encouraging more participation and result. As the practice centers grow, they become self-sufficient and less dependent on support (Shih, Chang \& Lin, 2010).

The Lessons Learned Approach: "The lessons learned approach to the strategy of best practices and knowledge transfer places lessons learned from past crises into an outline database which is accessible to all at all times in the worldwide system of the organization (internet). A good example of this approach is in the National Security Agency (NSA) internet that contained three categories of lessons learned. These are firstly informal (which feature lessons such as how to go on temporary duty during an emergency situation, secondly, success which documents what goes well during a crises or other situations; and thirdly; problems, which provides a description of an annoying situation with recommended solutions” (Shih, Chang \& Lin, 2010: 75). 
Customer Focused Knowledge: This third strategy focuses on capturing knowledge about customers, developing and transforming knowledge and undertaking the needs of the customer, his preference and businesses. This is 'aimed at increasing overall turnover as well as bringing the organizational knowledge to bear on customer problems. The general belief here is that if the organization could make their customers successful, their own success would be secured as well. In order to be able to identify the intellectual capital associated with their precept, the organization should try to find the stream of logic that leads to the individual component that affects the customer's success' (Seyed, 2017).

Personal Responsibility for Knowledge: This strategy stems from the belief that people are the engine of knowledge and as such should be assisted and supported at all times. It is also "the belief that individuals are personally responsible for identifying, maintaining and expanding their own knowledge as well as understanding, renewing and sharing their knowledge assets. This strategy is in line with the emerging paradigm that employees are the ultimate source of new knowledge in a firm and that they are responsible for their own knowledge development. Expecting employees to take personal responsibility for their own knowledge and the knowledge of such organization entrusted to them is essentially an example of a pull-strategy initiated by the individual rather than that pushed by the organization. The practical working of the strategy was found at SKANDIA AFS (USA) where knowledge management was the responsibility of everyone in the organization and was manifested in their jobs. For instance, IT employees focused on packaging knowledge into IT products that support knowledge sharing while accounting people was responsible for developing the indicators to measure knowledge management activities. There was no specific percentage of time allotted to these knowledge management activities; instead, knowledge management was viewed as a philosophy of working. Another factor involved was the firms' organizational structure. For the simple reason that the firm did not take a hierarchical approach to culture was one of high thrust that fostered shared learning and emphasized self-management and support of initiatives” (Seyed, 2017: 534).

Intellectual Asset Management Strategy: This strategy emphasizes enterprise-level management of specific intellectual assets, such as patents, technologies, operational and management practices, customer relations, organizational managements, and other structural knowledge assets. This strategy can be "pursued by focusing on attaching financial measures to organizational knowledge or assets and then linking them to the organization's current and future performance. Effectiveness of this strategy is seen in SKAND1A and AFS. They were one of the early organizations to employ this strategy of making intellectual asset valuation a part of the supplement to its annual report to shareholders. They focused on the need to continually renew their intellectual assets to enhance the future prospects of their organization. Dow chemical company based in USA provides a good example of this strategy in action by using an Intellectual Asset Management process to improve management of intellectual assets. With this, the organization was able to transform accounting clerks to pro-active strategists. When the initiative started, the organization's intellectual asset managers found significant costsaving opportunities by reducing the tax maintenance for patents. This was an era that was easy to measure as it opened up opportunities and built credibility for future initiatives within Intellectual Asset Management. This was defined to include patents, copyrights, trade secrets, trademarks, and know-how. At Dow chemical company, Intellectual Asset Management was broadly focused and recognized more of the value contribution of all 
intellectual assets. The focus was on "value management" rather than on knowledge management since the company viewed knowledge management as purely a vehicle for value management” (Cohen, 2013: 8).

Innovation and knowledge Creation: This strategy emphasized innovation and the creation of new knowledge through basic and applied research and development. This is achieved through the provision of funds for expenses such as Research and Development (R \& D), contracts, conference fees and travel for other purposes such as field resting or data collection as well as purchase of both soft and hardware, books and other items that may be associated with a specific project strategy. This strategy can also be applied through the use of in-house agency workers to be released from their current duties either on a fulltime or part-time basis to pursue their projects. This strategy was successfully adopted by the National Security Agency in USA and it yielded positive results. The above strategies if properly applied could in no small measure help most organizations to overcome the problem of knowledge management in their organizations. It will help the organizational process that enhances synergistic combination of data and information-processing capacity of information technologies and the creative and innovative capacity of the employees within the organization. They will help the organization to easily identity, collect, analyze, use and adapt to the various knowledge that exists within the organization (Sayed, 2015).

\section{Conclusion}

Knowledge and information have become the medium in which business problems occur. As a result managing knowledge represents the primary opportunity for achieving substantial savings, significant improvements in human performance and competitive advantage. This paper therefore concludes that quality, efficiency and effectiveness in performance cannot happen if employees are not developed. Organizations compete today on the basis of knowledge since products and services are increasingly complex. This is why; the requirement for a life-long learning has become an unavoidable reality. Knowledge management has become crucial in business operations because the market is becoming too competitive and the rate of innovation is rising. Downsizing staff for instance also creates a need to replace informal knowledge with formal methods. Knowledge management is of importance because early retirements and increasing mobility of the work force lead to loss of knowledge. Again, the changes in strategic direction can result in the loss of knowledge in some specific areas of work activities.

\section{References}

1. Ahmed, H.M.Z., \& Mohamed, M.S. (2017). The effect of knowledge management critical success factors on knowledge management effectiveness and performance: An empirical research in Egyptian banking sector. The Business and Management Review Journal, 9(2), 201 - 211.

2. Akinyemi, B.O. (2007). Organizational knowledge management in the new economy in Nigeria.NIM Journal, 43(2), 1 - 20

3. Akram, K. \& Hilman, H. (2018).Effect of knowledge management activities and dynamic capabilities on employee performance in the banking sector. Empirical Evidence from Pakistan Studies in Business and Economics Journal, 13(2), 41 - 60. http://doi.org/10.2478/sbe-2018-0019

4. Armstrong, M. (2006). A handbook of HRM practice (8thed). London: Kogan page limited. 
5. Awan, A.G., \& Jabbar, A. (2015).The determinants of capital inflow in developing countries with reference to Pakistan. Developing Countries Studies, 4(12), 20 - 34.

6. Aygul, K. \& Bahtisen, K. (2017). The determination of knowledge, application and health beliefs of third and fourth grade nursing students regarding breast self exam. J. Breast Health Journal, 5(13), 10 15, doi: 10.5152/tjbh.2016.3207

7. Bergeron, B. (2003). Essentials of knowledge management. Hoboken, New Jersey: John Willey \& Sons, Inc.

8. Beyer, H., \& Hoflzbatt, K. (1997). Contextual design: A customer centred system approach system design, Morgan Kaufman New York.

9. Bosua, R., \& Venkitachalam, K. (2013).Aligning strategies and processes in knowledge management: A framework. Journal of Knowledge Management, 17(3), 331 - 346. https://doi.org/10.1108/JKM-10-2012-0323

10. Cohen, E. (2008). Left brain management strategies for right brain firms step magazine (online) http//www. Step insided.com. magazine/Article/28887. Accessed 1 August, 2009.

11. Cohen, W.A. (2013). The knowledge practice Drucker: to applying the wisdom of the world's greatest management thinker. New York: Amacon Publishing House.

12. Daft, R. (2012). Organizational theory and design New York Cengage Learning. Journal of Knowledge Management, 5(2), 50-78.

13. Davenport, T., \& Klahr, S. (1999). Knowledge management and the broader firm: strategy, Advantage and performance in Liebowitz, J. (ed) knowledge Handbook. Boca Raton, 1(1), 1 - 11.

14. Davenport, T., \& Prusak, L. (2005). Working knowledge: How organizations do what they know? Repeated work by permission. London: Harvard Business School Press.

15. Desouza, K.C. (2011). An introduction to knowledge management in K.C. Desouza \& A. Paquett (Eds.). knowledge management: An introduction. New York: Meal-Schman Publisher Inc.

16. Donate, M. J., \& Lanales, J.I. (2012). A new approach to the concept of knowledge strategy. Journal of Knowledge Management, 16(1), 22 - 44. https://doi.org/10.1108/13673271211198927

17. Drucker, P.F. (1989). The new realities. New York, Harper and Row.

18. Epetimehin, F.M., \& Ekundayo, O. (2011). Organizational knowledge management: survival strategy for Nigeria insurance industry. Interdisciplinary Review of Economics and Management, 1(2), 9 15.

19. Gao, F., Li, M., \& Nakamori, Y. (2008). Critical systems thinking as a way to manage knowledge. Systems Research Behavioural Science Journal, 1(11), 10 - 30. https://doi.org/10.1002/sres.512

20. Grant, R.M. (2006). Towards knowledge -based theory of the firm. Strategies Management Journal, 12(20), 109-122

21. Grey, D., \& Newman, B. D. (2002).The knowledge management forum http//www.kmforum.org/whatishtm (Accessed 2007 June 18).

22. Hankanson, L. (2010). The firm as an Epistemic Community: Knowledge based view revisited. Industrial and Corporate Change, 19(6), 18-28. https://doi.org/10.1093/icc/dtq052

23. Hayat, A., \& Riat, S. (2011). Analysis of knowledge management in the public sector of Pakistan. European Journal of Social Sciences, 19(3), 471 - 478.

24. Holsapple, C.W., \& Wu, J. (2011).An elusive antecedent of superior firm performance. The knowledge management factors. Decision Support Systems, 52(1), 271-283. https://doi.org/10.1016/j.dss.2011.08.003

25. Ibrahi, N., \& Reig, H. (2009). What is the value of knowledge practices? Electronic Journal on Knowledge Management, 1(2), $103-112$.

26. Karuoya, L.N., \& Thomas, A. S (2017). Knowledge management and the occasional links with performance. Journal of Knowledge Management, $7(3), \quad 67 \quad-\quad 81$. https://doi.org/10.1108/13673270310485631

27. Lekhanath, K., \& Santosh, R.P. (2017). Knowledge management, employee satisfaction and performance: Empirical evidence from Nepal Saudi Journal of Business and Management Studies, 2(10), 82 $-91$.

28. Nonaka, I., \& Takeuchi, P. (1995). The knowledge creating company: how Japanese companies create the dynamics of innovation Oxford, Oxford University Press.

29. Nonaka, I. (1991). The knowledge creating company New York University Press. 
30. Odiri, V.I.O. (2006). Towards ensuring effective knowledge management in organization - The role of human resource department, unpublished.

31. Odiri, V.I.O. (2014). Knowledge management and organizational performance in selected oil companies in Nigeria. Phd thesis in the department of Business administration, Delta state university, Abraka (unpublished)

32. Okunoye, A. (2002). Where the global needs the local: variation in enablers in the knowledge management process. Journal of Global Information Technology Management, 4, 18 - 32. https://doi.org/10.1080/1097198X.2002.10856329

33. Onyango, R.A. (2018). Effects of knowledge management practices in financial institutions: A study of lion asset management limited in Nairobi. Kenya: University Press

34. Ou-Yang, L. (2014). Cyclic Model for knowledge management capability. A review study Arab Journal of Business Management Performance, 4(4), 1-9. http://dx.doi.org/10.4172/2223-5833.1000118

35. Popov, S., \& Vlasov, M. (2014).Managing knowledge generation at universities in C. Vivas and P. Sequeiraeds 2014.Proceedings of the European Conference on Knowledge Management, 2(1), 811-816.

36. Roy, S. K., \& Sivakumar, Y. (2011). Leveraging collaborative technologies to build knowledge sharing culture at hp analytics. MIS Quarter Executive, 10(1), 1-18

37. Salisbury, M. \& Plass, J. (2001).A conceptual framework for a knowledge management system. Human Resources Development International, 13(3), 10 - 19. https://doi.org/10.1080/13678860010016913

38. Salman, B. M., \& Sumaiya, S. (2017). Organization of knowledge management in knowledge intensive Pakistani banks: a qualitative case study. Knowledge and Performance Management Journal, 1(1), $36-45$.

39. Sanchez, K. (1997). Managing articulated knowledge in competence - based competition in knowledge as a business resource. Valentine: Copenhagen.

40. Sayed, H.S. (2015).Effective factors of successful implementation of knowledge management in higher education. Management and Administration Science Review, 4(1), 166 - 1811

41. Seyed, K.V. (2017). Application of knowledge management in organizational management.Iran's Ministry of Sciences, Research and Technology Journal, 1(1), 533 - 537.

42. Shih, K.H., Chang, G., \& Lin, B. (2018).Assessing knowledge creation and intellectual capital in banking industry. Journal of Intellectual Capital, 11(1), 74-89. https://doi.org/10.1108/14691931011013343 43. Skyrme, D. (2003). Knowledge management: making sense of an oxymovon. Management Insight and Series, no 2, 56 - 70.

44. Thomas, J, W., \& Bizer, K. (2013).To protect or not to protect? Modes of appropriability in the small enterprise sector. Research Policy Journal, 42(1), 35 - 49. https://doi.org/10.1016/j.respol.2012.04.019 45. Valmohammadi, C., \& Ahmadi, M. (2015). The impact of knowledge management practices on organizational performance: A balanced score card approach. Journal of Enterprise Information Management, 28(1), 131-159. https://doi.org/10.1108/JEIM-09-2013-0066

46. Wang, S., Noe, R., \& Wang, Z. (2016).Motivating knowledge sharing in knowledge management system: a quasi-field management. Journal of Management, 4(4), $978 \quad$ - 1009. https://doi.org/10.1177/0149206311412192 Creative Commons Attribution - Non Commercial - No Derivatives 4.0 International License. 